\section{TRIAL BLEEDINGS.}

\section{To the Editor of The LANCET.}

Sir :-As a pupil of Dr. Marshall Hall, I must beg to call Mr. Ancell and your readers attention to an error in that gentleman's lecture, in your last Number. Dr. Hall has no where proposed the "trial bleedings," mentioned by Mr. Ancell. I shonld not have noticed this subject had not the original plan of Dr. Hall been of the first practical importance. I trust Mr. Ancell will be indaced; by this note, to read Dr. Hall's work, and give a true account of the sub. ject in his next lecture. He will find that Dr. Hall's proposition is limited to cases in which it is previously determined to be proper. At page 218 of the first volume of $T H F$ LANCET, for 1837,1838 , it is stated:-This proposition applies to every case in which it is required to bleed the patient fully; and " this is the plan which I recommend you to adopt. Determine the first question, that the case requires the full detraction of blood, by the history, symptoms, the diagno. sis," \&c. How different is all this from $\mathrm{Mr}$. Ancell's statement. "Cases now and then occur, in which it is difficult to determine whether bleeding is indicated, or the contrary." In such cases Dr. Marshall Hall recommends, \&c.

I will not close this note without recom. mending; to the consideration of the junior amongst your readers, Dr. Hall's most important rule for blood-letting. It is one, in the application of which $I$ have found the greatest satisfaction; it is one which has sometimes emboldened me to go on with a remedy at once powerful and safe : and it is one which has, in other cases, arrested me in a course of what would have been dangerous depletion. I am, Sir, your obedient servant,

Nemo.

MR. GRAY AND THE REV. MR. BURNES.

To the Editor of THE LANCET.

SrR:-In consequence of the Rev. J. Burnes, of Enon chapel, having waited upon me in reference to the letter which was inserted in the Lancet, I consider it my duty to apprise the public, that he is not the person who is connected with the Lung Hospi$t a l$ of $D_{r}$. Sherriffs, and therefore my obser. vations can have no reference to him. I was led into this error by Mr.C., a surgeon, who occasionally preaches for Mr. Burnes, who gratuitously called on, and gave the information to me respecting $\mathrm{Mr}$. Burnes. $1 \mathrm{am}$. Sir, yours,

Dec. 20th, 1839.

John Gray.

A NEW READING OF AN OLD SAYING.

Mr LYN exhibited to the students aud Sir Anthony, some needles which he had made for the purpose of trying Velpeau's method of abliterating . varicose veins, and expressed his opinion that they were not strong enough for the purpose. "You have only to pass them through a mould candle," said Sir "Tony," and they will be made pliable to operate with." "Teach your grand. mother to suck eggs," contemptuously cried Mr. Lynn. "Teach your grandmother to do what?" said the senior surgeon, "Why man, you have made a mistake in that vene. rable-saying, it is ' Teach your grandmother to cook eggs.?" Sir Anthony looked round for the approving smiles of the students, at his wonderful erudition.

Mr. MaYo.-This gentleman having called our attention to a note which was appended to the paper of Mr. ACTon in the last Number of THE LAncer, we have to inform Mr. Mayo, that it was written by the sub.editor, and did not happen to be submitted to the inspection of $\mathrm{Mr}$. W AKLEY before publica. tion. On referring to the sub-editor on the subject, and making known to him the com. plaint of Mr. MaYo, his reply is, that he " holds himself to be responsible for the im. "port of the remarks which the note con. "6 tains,"-ED. L.

The state of Mr. WALFORD's health has compelled that gentleman to retire from the Aldersgate-street School, wbich establish. ment Dr. W a LLER has again joined as lec. turer on midwifery.

\section{CORRESPONDENTS.}

Numerous correspondents have forwarded to us criticisms on the treatment of the case related by Mr. Simpson, but in each in. stance the contribution is anonymous. We will insert the first that is authenticated with a name and adaress for publication.

A Stranger in London. There is not in the metropolis such a libirary as is de. manded.

$M r . E . L .-W e$ do not doubt the pecuniary distress of the applicant. Habitual beggars are always in difficulties.

The letters from Middlesex Hospital Students next week.

The communications of $M r$ r. Lambton, $M r$. Gurney, Mr. Hy. Bond, Dr. Furniss, Medicus Monensis, $\boldsymbol{A}$ Student at Guy's, Mr', John Terence, Mr. Graves, and Mr. Matheusol, hare been received.

Monos has been received; so has the letter from Bristol, but the communication conld not be inserted this week. The engraving with Mr. Duke's has unavoidably been de. layed.

The reply to $A$ in Old Aprrentice cannot be given. He has every material for forming his judgment already before him in the pages of this Journal: Who can pronounce this year what will be the events of the next? 